\title{
Low-grade myxofibrosarcoma following a metal implantation in femur: a case report
}

\author{
Weisong Li ${ }^{1,2}$, Dan $\mathrm{Li}^{3^{*}}$, Xiansen Zhu', Shaohui $\mathrm{Lu}^{4}$, Chunlei $\mathrm{He}^{5}$ and Qingchun Yang ${ }^{1 *}$
}

\begin{abstract}
Myxofibrosarcoma is a myxoid variant of malignant fibrous histiocytoma that most commonly involves the extremities of elderly people. However, a primary myxofibrosarcoma with bone invasion in young adults is extremely rare. Herein, we report the case of a 31-year-old male with a gradually enlarging left thigh mass, who had a history of left femur fracture and received an open reduction and internal fixation with titanium alloy plates and screws 33 months previously. Imaging investigations revealed an irregularly shaped soft tissue mass around the left femur shaft and a partial bone defect in the middle one-third of the left femur. Pathological examination of the resected specimen showed a multi-nodular appearance, abundant myxoid matrix and elongated curvilinear capillaries. Immunohistochemical studies revealed that the tumor cells was positive for VIM and MDM2, and was negative for CK, MSA, SMA, DES, S-100 and CD34. Labeling index of Ki-67 was 25\%. Based on the morphological finding and immunostaining, it was diagnosed as a low-grade myxofibrosarcoma. The clinical and imaging examinations did not reveal the evidence of a primary cancer elsewhere, and the patient had no personal or family history of malignancy. To our knowledge, this is the first case of a primary myxofibrosarcoma developed following a fracture and metal implantation in young adults.
\end{abstract}

Virtual slides: The virtual slide(s) for this article can be found here: http://www.diagnosticpathology.diagnomx.eu/vs/ 1745984882113605

Keywords: Myxofibrosarcoma, Femur, Fracture, Titanium alloy, Metal implantation

\section{Background}

Myxofibrosarcoma is a myxoid variant of malignant fibrous histiocytoma (MFH), characterized by a nodular appearance, prominent myxoid matrix, elongated curvilinear capillaries, and location mostly in dermal and subcutaneous tissues in the extremities of elderly people [1-3]. In 1996, Mentzel et al. [3] reported 75 cases of myxofibrosarcomas and divided these tumors into low-, intermediate-, and high-grade categories, depending on the degree of cytologic atypia and the presence or absence of pleomorphic MFH-like lesion within the tumor. Tumors of the low-grade category showed a mainly myxoid with mild cytologic atypia, while high-grade tumors showed a pleomorphic appearance with multinucleated giant cells, high mitotic activity, and areas of necrosis.

\footnotetext{
* Correspondence: dan.li.liu@hotmail.com; qingchunyang@outlook.com ${ }^{3}$ Translational Medicine Research and Development Center, Shenzhen Institutes of Advanced Technology, Chinese Academy of Sciences, No. 1068 Xueyuan Avenue, Shenzhen, Guangdong 518055, China

'Department of Pathology, Gannan Medical University, No. 1, Yixueyuan Road, Ganzhou, Jiangxi 341000, China

Full list of author information is available at the end of the article
}

Several clinical studies of myxofibrosarcomas showed that approximately $80 \%$ of the tumors occurred in the extremities and about $12 \%$ in the trunk, with a high incidence in the dermal or subcutaneous tissues [1-3]. Other sites for myxofibrosarcomas included head and neck region, retroperitoneum, pelvis and heart $[3,4]$. However, a primary myxofibrosarcoma with bone invasion was rarely reported [5-11]. In addition, the peak age incidence of myxofibrosarcomas was in the fifth to seventh decades with a slight male predominance $[2,12]$.

Herein, we report a low-grade myxofibrosarcoma with left femur invasion in a 31-year-old male, and present the clinical, radiological and histopathological characteristics of this tumor. The clinical and imaging examinations did not reveal the evidence of a primary cancer elsewhere, and the patient had no personal or family history of malignancy. It is noteworthy that the patient had a history of left femur fracture and received an open reduction and internal fixation with titanium alloy plates and screws 33 months previously. To our knowledge, this is the first report on a primary myxofibrosarcoma 
that developed following a fracture and metal implantation in young adults.

\section{Case presentation}

A 31-year-old male patient has a history of a multiple fracture involving the left femur shaft, the middle and distal segment of the left tibiofibula, as a result of a traffic accident in October 2008. Subsequently, the patient underwent an open reduction and internal fixation (ORIF), using titanium alloy plates and screws. Ten months after ORIF, an X-ray examination showed no displacement of the fracture site, and the bridging callus was visible on two standard views with partial obliteration of the fracture line. However, the patient did not undergo reoperation to remove the metal implants due to financial difficulties.

In August 2011, the patient complained of a 3-month history of a gradually enlarging left thigh mass. Physical examination revealed a $12 \times 10 \mathrm{~cm}$ firm, tender and fixed mass in the anteromedial left thigh, with local superficial venous engorgement and skin temperature increment. Percussion pain in the axial direction of the left lower limb was absent. The inguinal lymph nodes were not palpable. Routine chest radiograph and abdominal ultrasound examination showed no abnormalities. Other routine tests, including plasma biochemistry, liver function tests and urinalysis, were normal.

The X-ray examination demonstrated an ill-defined osteolytic lesion with disappearance of the medial cortical bone in the middle of the left femur shaft, as well as an ambiguous image of a soft tissue mass. Computed tomography $(\mathrm{CT})$ images clearly showed a partial bone defect approximately $9.7 \mathrm{~cm}$ in length on the medial border of the left femur shaft. A $9.7 \times 11 \times 19 \mathrm{~cm}$ irregularly shaped soft tissue mass was observed around the left femur, with the surrounding tissues compressed and shifted significantly (Figure 1). CT findings also showed that the soft tissue mass was heterogeneous in density with CT value of $36 \mathrm{HU}$, in which small pieces of slightly high-density lesions were found. These imaging findings suggested that the mass was neoplastic.

Tissue biopsy was performed, and histopathological examination reported that the tumor was predominantly composed of a large number of diffuse fusiform cells and myxoid matrix. The fusiform tumor cells were arranged in a multi-nodular pattern, with indistinct cell margins, slightly eosinophilic cytoplasm, and hyperchromatic atypical nuclei. Mitoses were infrequent. In addition, many elongated curvilinear capillaries were observed (Figure 2). These cytological findings suggested a malignant tumor of mesenchymal origin.

On 3 September 2011, the patient underwent operation for the metal implants removal and tumor resection. Intraoperative findings indicated that the tumor infiltrated into the middle of the femur shaft and the surrounding tissues including the rectus femoris, sartorius, pectineal muscle, long adductor muscle, gracilis muscle, vastus medialis, vastus lateralis, vastus intermedius, and biceps femoris. The tumor and bone tumor segment approximately $15 \mathrm{~cm}$ in length were resected, and the surgical margin was microscopically free of tumor. Sequential bone defect reconstruction after tumor resection was performed by reimplantation with the alcohol inactivated bone tumor segment, in which the vascularised autologous left fibula approximately $18 \mathrm{~cm}$ in length was inserted. Then, an internal fixation with titanium alloy plates and screws was once again performed, and a closed vacuum drainage system was used.

Macroscopically, the excised specimen was a grayishwhite or grayish-brown mass measured $7 \times 14 \times 10 \mathrm{~cm}$. On the cut section, a fish-like appearance with central necrosis area was observed. Microscopic features were identical to that of the biopsy. Immunohistochemical studies showed that the tumor cells expressed strong immunoreactivity for vimentin (VIM) and negative for cytokeratin (CK), suggesting a mesenchymal histogenesis (Figure 3a and b). Labeling index of Ki-67 (the number of Ki-67 positive tumor cells divided by the sum of Ki-67 positive and negative tumor cells) was 25\% (Figure 3c). Muscle-specific actin (MSA), smooth muscle actin (SMA) and desmin (DES) were negative in the tumor cells, eliminating the possibility of a muscle-derived tumor (Figure 3d-f) [13]. The negative expression of S-100 protein eliminated a tumor of neural or adipose tissue origin (Figure $3 \mathrm{~g}$ ). The tumor cells were negative for cluster of differentiation 34 (CD34) (Figure 3h), B cell lymphoma/ lewkmia-2 and anaplastic lymphoma kinase, which eliminated the possibility of a solitary fibrous tumor or inflammatory myofibroblastic tumor [14]. Interestingly, the positive staining of CD34 in vascular endothelial cells highlighted the curvilinear capillaries, which was an important histological feature of myxofibrosarcoma. In addition, positive expression of murine double minute 2 (MDM2) was observed in the tumor cells. Although MDM2 immunostaining is useful adjunct in diagnosing well-differentiated and dedifferentiated liposarcoma subtypes, overexpression of MDM2 has also been reported in a small number of myxofibrosarcomas [15-17]. The combination of clinical and pathological features revealed a low-grade myxofibrosarcoma.

The patient received three cycles of postoperative adjuvant chemotherapy with a combination of ifosfamide, doxorubicin, cisplatin and mesna, and he experienced no special discomfort during chemotherapy. In June 2012, the patient underwent the third operation for the removal of metal implants due to implant breakage in an accidental fall, followed by external fixation.

However, in June 2013, only 22 months after tumor resection, a firm and painless mass approximately $5 \mathrm{~cm}$ in 

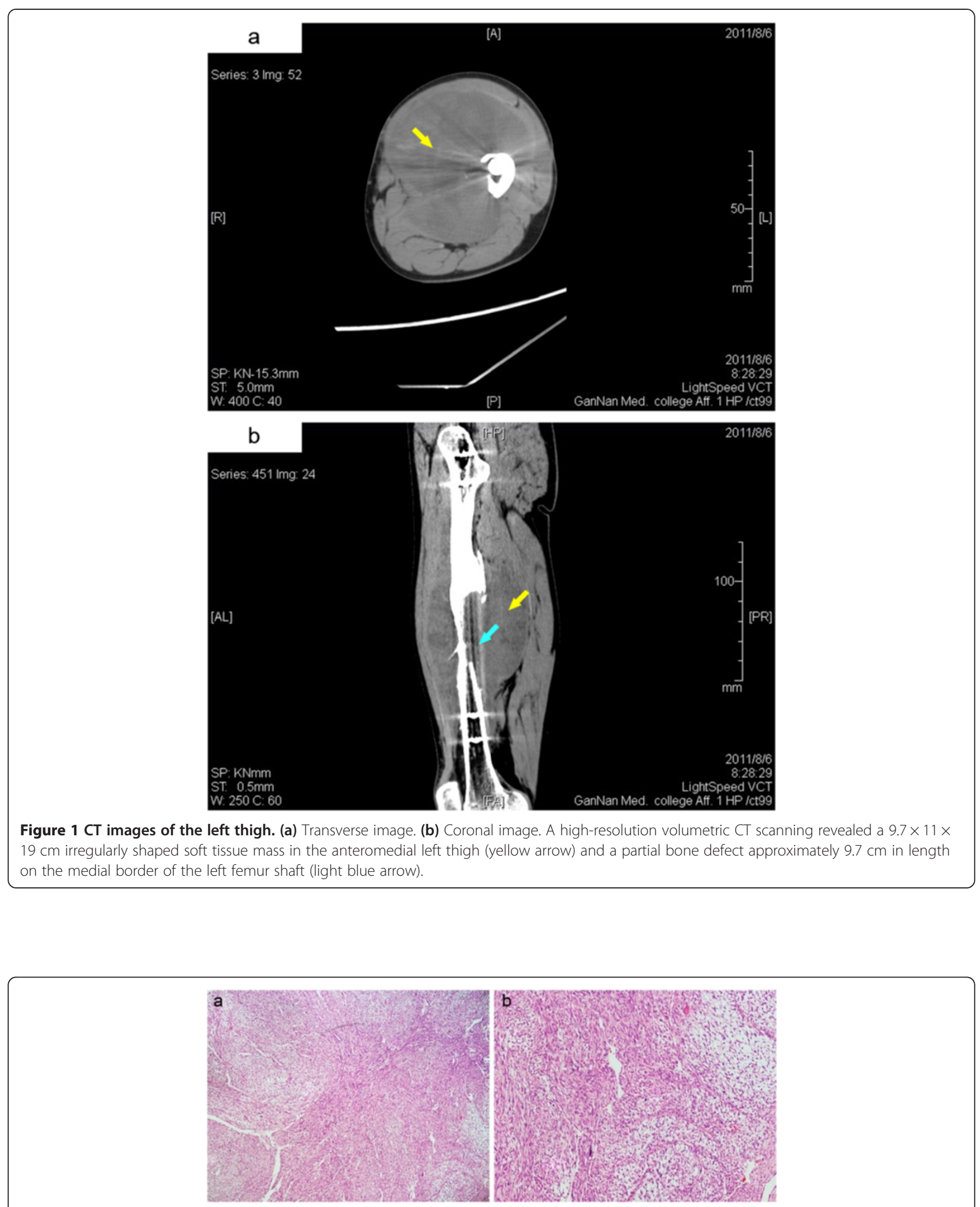

Figure 2 Histopathological examination of the tumor. (a) Magnification, $\times 40$. (b) Magnification, $\times 100$. H\&E staining showed that the tumor was predominantly composed of a large number of diffuse fusiform cells and myxoid matrix. The fusiform tumor cells were arranged in a multi-nodular pattern, with indistinct cell margins, slightly eosinophilic cytoplasm, and hyperchromatic atypical nuclei. Mitoses were infrequent. Many elongated curvilinear capillaries were observed. 


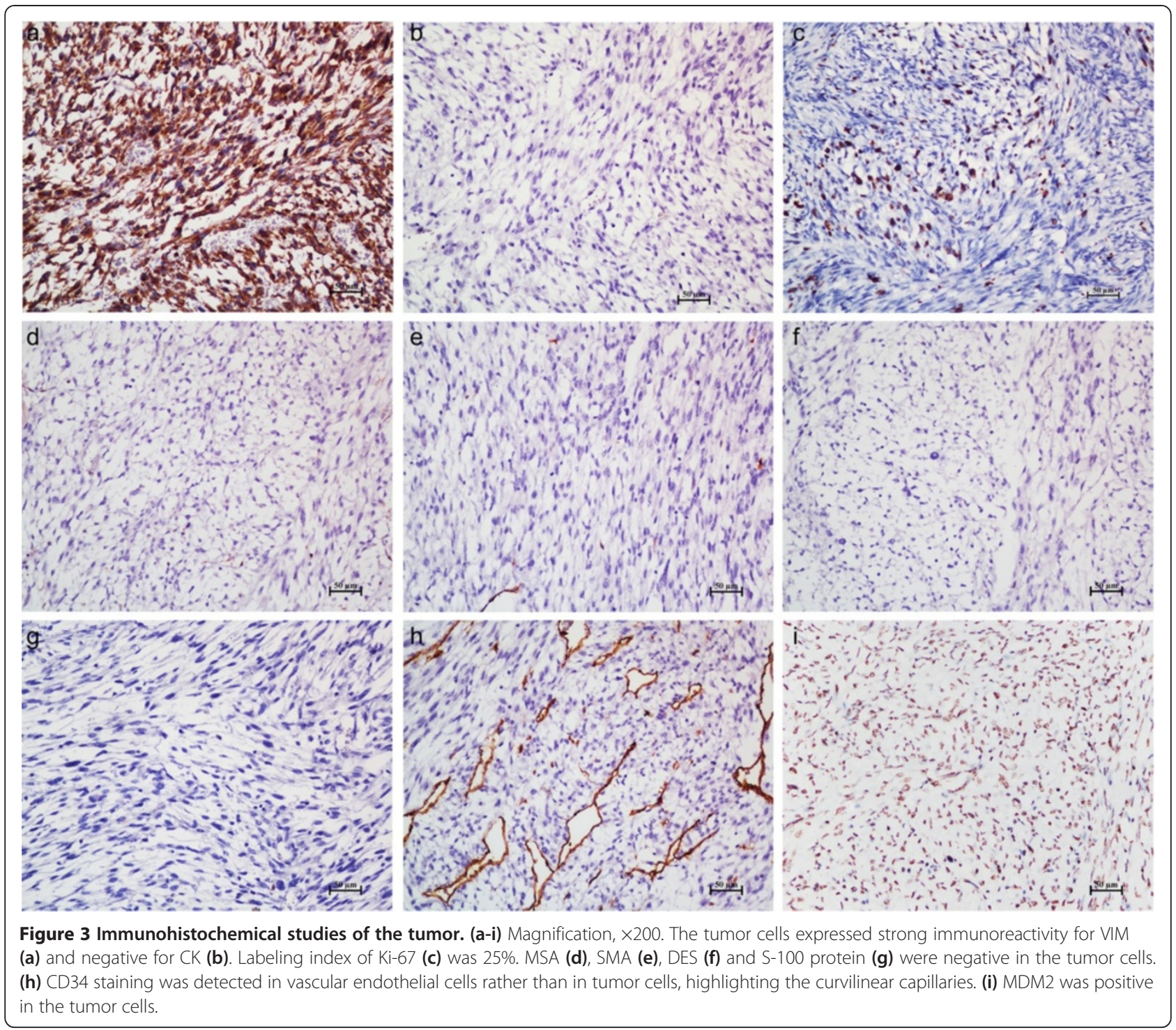

diameter was palpated in the medial left thigh. Magnetic resonance imaging (MRI) showed an irregular soft tissue mass with ill-defined margin in the anteromedial left thigh, accompanied by surrounding soft tissue swelling and normal muscle structure disappearance. Additionally, bone destruction in the left femur shaft was also observed (Figure 4). Tissue biopsy was performed and histopathological examination showed that the tumor exhibited the classical histological features of myxofibrosarcoma, including a nodular appearance, prominent myxoid matrix and elongated curvilinear capillaries. The morphology of the tumor cells varied from small and bland to enlarged, bizarre, pleomorphic and multinucleated, suggesting increased atypia and pleomorphism compared with those in the primary tumor (Figure 5). The combination of clinical and pathological features revealed a recurrent myxofibrosarcoma with higher malignancy.
There was no evidence of distant metastasis. The patient eventually underwent left hip disarticulation due to the inability to control the tumor progression.

\section{Discussion}

Myxofibrosarcoma, also known as a myxoid variant of $\mathrm{MFH}$, is one of the most common sarcomas in the extremities of elderly people, characterized by a high frequency of local recurrence. Distinctive histological features included the following: a commonly nodular growth pattern; a myxoid matrix containing elongated, curvilinear capillaries; and fusiform, round or stellate tumor cells with indistinct cell margins, slightly eosinophilic cytoplasm, and hyperchromatic atypical nuclei [3]. These lesions varied from a hypocellular, mainly myxoid, and purely spindle-cell appearance (low-grade neoplasms) to high-grade, pleomorphic (MFH-like) lesions 

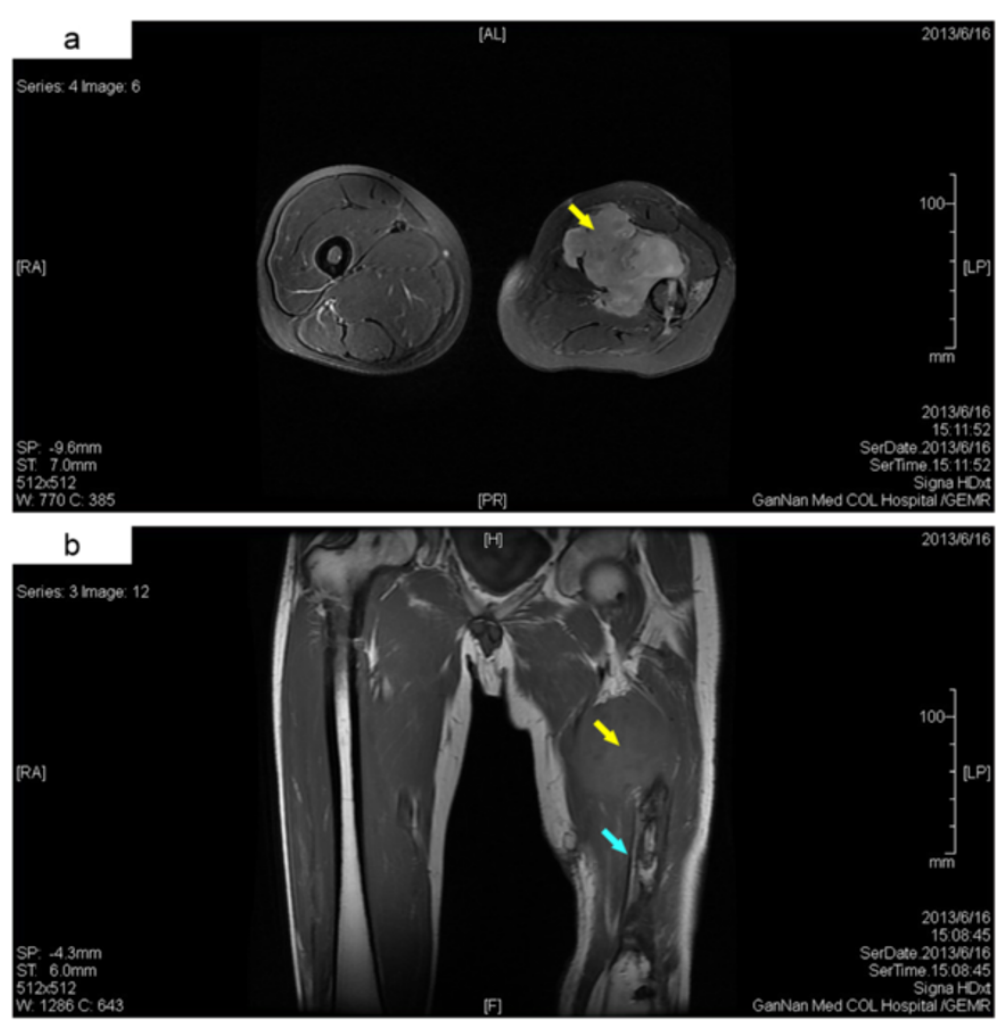

Figure 4 MRI images of the thigh. (a) Transverse T2-weighted image. (b) Coronal T1-weighted image. MRI images showed an irregular soft tissue mass with ill-defined margin in the anteromedial left thigh (yellow arrow), accompanied by surrounding soft tissue swelling and normal muscle structure disappearance. Bone destruction in the left femur shaft was observed (light blue arrow).

with multinucleated giant cells, high mitotic activity, and areas of necrosis [3]. The most common sites for this tumor are the extremities, predominantly subcutaneous. Primary myxofibrosarcomas with bone invasion were rarely occurred, with no more than 15 previous cases worldwide being reported in the literature [5-11]. Five of these patients developed myxofibrosarcoma in a long bone of the extremities, with an average age of 53.2 years (range, 31 to 84). The clinicopathological features of them were summarized in Table 1.
The etiology of myxofibrosarcoma remains unknown. It was previously reported that 2 patients developed a myxofibrosarcoma after radiotherapy $[18,19]$. In the current case, the patient developed a low-grade myxofibrosarcoma in the left thigh after a multiple fracture and metal implantation suffered about 3 years ago. The patient was a farmer with no known history of potential environmental hazardous substances exposure, and he was an occasional smoker and did not drink alcohol. Except for receiving a metal implantation for osteosynthesis, the patient had

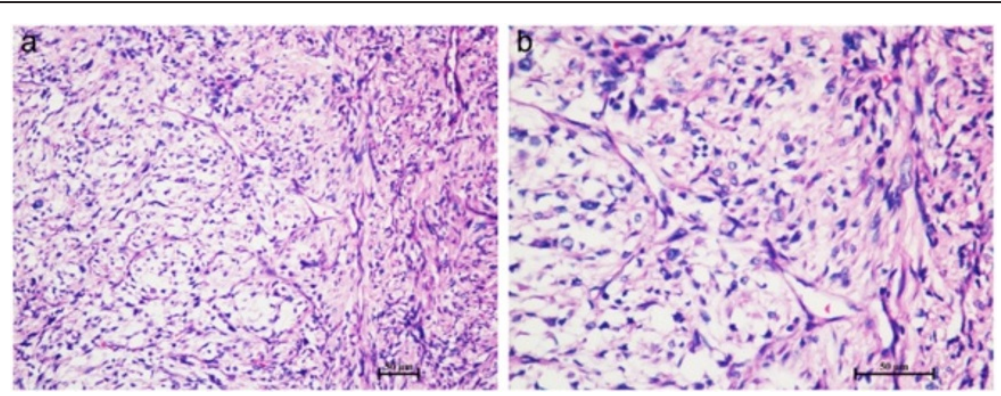

Figure 5 Histopathological examination of the recurrent tumor. (a) Magnification, $\times 200$. (b) Magnification, $\times 400$. H\&E staining showed that the tumor cells exhibited increased atypia and pleomorphism compared with those in the primary tumor, varying from small and bland to enlarged, bizarre, pleomorphic and multinucleated. Abundant myxoid matrix and elongated curvilinear capillaries were also observed. 
Table 1 Clinicopathological features of the reported cases of myxofibrosarcomas in bone of the extremities

\begin{tabular}{|c|c|c|c|c|c|c|c|}
\hline Reference & Year & $\begin{array}{l}\text { Age (y)/ } \\
\text { sex }\end{array}$ & Size & Location & Histology & Immunohistochemistry & Follow up (y) \\
\hline Kapur P et al. [5] & 2004 & $31 / M$ & $\begin{array}{l}5 \mathrm{~cm} \text { in maximum } \\
\text { dimension }\end{array}$ & Left tibia & $\begin{array}{l}\text { nodular contour; myxoid stroma; } \\
\text { spindle to stellate cells with mild } \\
\text { cytologic atypia and rare mitoses }\end{array}$ & $\begin{array}{l}\text { VIM (+), MSA (+), SMA (+), } \\
\text { CD68 (-), Mac-387 (-), } \\
\text { factor XIIIa }(-), \text { DES }(-)\end{array}$ & Not reported \\
\hline Marotta D et al. [6] & 2009 & $84 / M$ & $8 \times 5 \mathrm{~cm}$ & Left tibia & $\begin{array}{l}\text { spindle cells; polygonal epithelioid } \\
\text { cells with pleomorphism and } \\
\text { elevated mitotic index; necrosis }\end{array}$ & $\begin{array}{l}\text { CD34 }(-) \text {, SMA }(-) \text {, DES }(-) \text {, } \\
\text { caldesmon }(-), \text { CK }(-), \\
\text { S-100 (-) }\end{array}$ & 2 \\
\hline Romeo $S$ et al. [7] & 2012 & $39 / M$ & Not reported & Lower limbs & $\begin{array}{l}\text { spindle cells; myxoid stroma; } \\
\text { elongated curvilinear thin-walled } \\
\text { blood vessels }\end{array}$ & $\begin{array}{l}\text { CK }(-), \text { EMA }(-), \text { SMA }(-), \\
\text { DES }(-) \text {, caldesmon }(-)\end{array}$ & 1.8 \\
\hline Romeo $S$ et al. [7] & 2012 & $44 / F$ & Not reported & Lower limbs & $\begin{array}{l}\text { spindle cells; myxoid stroma; } \\
\text { elongated curvilinear thin-walled } \\
\text { blood vessels }\end{array}$ & $\begin{array}{l}\text { CK }(-), \text { EMA }(-) \text {, SMA }(-), \\
\text { DES }(-) \text {, caldesmon }(-)\end{array}$ & 6 \\
\hline Romeo $S$ et al. [7] & 2012 & $68 / M$ & Not reported & Lower limbs & $\begin{array}{l}\text { spindle cells; myxoid stroma; } \\
\text { elongated curvilinear thin-walled } \\
\text { blood vessels }\end{array}$ & $\begin{array}{l}\text { CK }(-), \text { EMA }(-), \text { SMA }(-), \\
\text { DES }(-) \text {, caldesmon }(-)\end{array}$ & 13 \\
\hline
\end{tabular}

no relevant medical or family history. In addition, the patient has no clinical or radiological evidence of a neoplasm elsewhere in the body, excluding the possibility of a secondary lesion.

There were some literatures about the tumors developed following a bone fracture. URIST [20] reported a desmoid tumor developed following a simple fracture of the radius and ulna. Langer et al. [21] reported a case of a 19-year-old man who developed a giant cell tumor in the distal ulna following a scaphoid fracture. However, whether pure fracture plays a role in the genesis of primary bone tumors remains controversial, because of the lack of direct evidence. In addition, a series of literatures have been published with emphasis on the potential carcinogenic effect of metal implants. As early as 1956, Oppenheimer et al. [22] observed the carcinogenic effect

Table 2 Patients with tumors at the site of metal implants

\begin{tabular}{|c|c|c|c|c|c|c|}
\hline Reference & Year & $\begin{array}{l}\text { Age (y) at } \\
\text { implant/sex }\end{array}$ & $\begin{array}{l}\text { Implant } \\
\text { site }\end{array}$ & Implant material & Tumor type & $\begin{array}{l}\text { Latent } \\
\text { period }(y)\end{array}$ \\
\hline McDougall A [23] & 1956 & $12 / \mathrm{M}$ & Humerus & $\begin{array}{l}\text { Stainless steel plate (FeCrNi) and } \\
\text { screws (FeCr) }\end{array}$ & Ewing's sarcoma & 30 \\
\hline Delgado ER [24] & 1958 & $37 / M$ & Tibia & Eggers' plate and screws & Osteosarcoma & 3 \\
\hline Dube VE et al. [25] & 1972 & $58 / \mathrm{M}$ & Tibia & Steel plate and screws & Hemangioendothelioma & 26 \\
\hline Tayton KJ [26] & 1980 & $4 / F$ & Femur & Sherman plate (CoCrMo) and screws & Ewing's sarcoma & 7 \\
\hline McDonald I [27] & 1981 & $31 / \mathrm{M}$ & Tibia & Sherman plate (CoCrMo) and screws & Histiocytic lymphoma & 17 \\
\hline Penman HG et al. [28] & 1984 & $75 / F$ & Hip & Cobalt-chrome prosthesis & Osteosarcoma & 16 \\
\hline Bagó-Granell J et al. [29] & 1984 & $75 / F$ & Hip & Charnley-Müller prosthesis & Malignant fibrous histiocytoma & 2 \\
\hline Swann M [30] & 1984 & $63 / M$ & Hip & McKee-Farrar prosthesis (CoCrMo) & Malignant fibrous histiocytoma & 3 \\
\hline Weber PC [31] & 1986 & $76 / F$ & Knee & CoCrMo prosthesis & Epitheliod sarcoma & 4.5 \\
\hline Hughes AW et al. [32] & 1987 & $14 / \mathrm{M}$ & Femur & Sherman screw (CoCr) & Malignant fibrous histiocytoma & 29 \\
\hline Haag M et al. [33] & 1989 & $69 / F$ & Hip & Weber-Huggler prosthesis & Malignant fibrous histiocytoma & 14 \\
\hline Ward JJ et al. [35] & 1990 & $65 / F$ & Femur & Smith-Petersen nail & Osteosarcoma & 9 \\
\hline Khurana JS et al. [36] & 1991 & $25 / \mathrm{M}$ & Femur & Hansen Street intramedullary nail & Malignant fibrous histiocytoma & 14 \\
\hline Gatti GM et al. [37] & 1999 & $37 / M$ & Femur & Stainless steel implant & Rhabdomyosarcoma & 11 \\
\hline Hinarejos P et al. [38] & 2000 & $28 / \mathrm{M}$ & Tibia & Stainless steel plate and screws & Fibrosarcoma & 30 \\
\hline Adams JE et al. [39] & 2003 & $63 / M$ & Hip & Titanium and cobalt alloy prosthesis & Osteosarcoma & 3 \\
\hline Albert A et al. [40] & 2009 & $75 / F$ & Knee & Insall Burstein prosthesis & Angiosarcoma & 10 \\
\hline Palraj B et al. [41] & 2010 & $70 / \mathrm{M}$ & Tibia & Stainless steel plate and screws & Anaplastic large T-cell lymphoma & 7 \\
\hline Dorrestijn O et al. [42] & 2011 & $58 / \mathrm{M}$ & Femur & Unreamed intramedullary nail & Osteosarcoma & 2 \\
\hline
\end{tabular}


of silver, tantalum, vitallium and stainless steel by subcutaneously embedding metal foils in rats. Clinical studies on the carcinogenicity of metal orthopedic implants showed that a similar tumor category, predominantly sarcomas, developed at the implant site and the latent periods for tumor development ranged from 2 years to more than 30 years [23-42]. The detailed information of these cases was listed in Table 2. There was no specific association between tumor type and metal material. In this case, the metal implants were made of titanium alloy. Adams et al. [39] reported a case of a high-grade osteosarcoma occurring at the site of a modular porous-surfaced titanium and cobalt alloy total hip prosthesis 3 years after device implantation. Nuevo-Ordóñez et al. [43] detected an increased titanium concentration in the serum of patients with different types of titanium implants. Although the local and systemic long-term effects of titanium particles on the human organism were unknown, their toxic effects were revealed in cell cultures [44]. This study showed that the particulate debris from a titanium metal prosthesis induced genomic instability, mainly consisting of chromatid breaks and reproductive failure, in primary human fibroblast cells. These delayed effects were similar to those caused by heavy metals cadmium and nickel [44].

Case reports of malignant tumors at the site of metal implants in humans and domestic animals have implicated carcinogenesis as a potential, although rare, complication of metal orthopedic implants. The actual incidence of tumors in association with metal implants cannot be reliably estimated, considering that clinicians and veterinarians are not obliged to report adverse reactions to implants. Although the possibility that the apparent association is coincidental cannot be excluded, orthopedic surgeons should be aware of the potential carcinogenic risk of metal implants.

\section{Conclusion}

In summary, we described a case of low-grade myxofibrosarcoma with bone invasion, which developed following a fracture and metal implantation in a young adult. To our knowledge, this case is the first report of primary myxofibrosarcoma in association with titanium alloy implants, which should alert doctors to the possible carcinogenic risk of titanium alloy implants.

\section{Consent}

Written informed consent was obtained from the patient for publication of this Case report and any accompanying images. A copy of the written consent is available for review by the Editor of this journal.

\footnotetext{
Abbreviations

CD34: Cluster of differentiation 34; CD68: Cluster of differentiation 68; CK: Cytokeratin; CT: Computed tomography; DES: Desmin; MDM2: Murine double minute 2; MFH: Malignant fibrous histiocytoma; MRI: Magnetic
}

resonance imaging; MSA: Muscle-specific actin; ORIF: Open reduction and internal fixation; SMA: Smooth muscle actin; VIM: Vimentin.

\section{Competing interests}

The authors declare that they have no competing interests.

\section{Authors' contributions}

WSL, DL and QCY collected the data, planned and drafted the manuscript. WSL and XSZ were the pathologists who evaluated the specimen. SHL was the radiologist who provided the radiology images. CLH was the clinician who cared for the patient and provided the clinical data. All authors read and approved the final manuscript.

\section{Acknowledgements}

We thank Qinhe Fan, Department of Pathology, the First Affiliated Hospital, Nanjing Medical University, Nanjing, China for helping in pathological diagnosis.

\section{Author details}

'Department of Pathology, Gannan Medical University, No. 1, Yixueyuan Road, Ganzhou, Jiangxi 341000, China. ${ }^{2}$ Department of Pathology, the First Affiliated Hospital, Sun Yat-Sen University, No. 58, Zhongshan Road II, Guangzhou, Guangdong 510080, China. ${ }^{3}$ Translational Medicine Research and Development Center, Shenzhen Institutes of Advanced Technology, Chinese Academy of Sciences, No. 1068 Xueyuan Avenue, Shenzhen, Guangdong 518055, China. ${ }^{4}$ Department of Radiology, the First Affiliated Hospital, Gannan Medical University, No. 23, Qingnian Road, Ganzhou, Jiangxi 341000, China. ${ }^{5}$ Department of Orthopedics, the First Affiliated Hospital, Gannan Medical University, No. 23, Qingnian Road, Ganzhou, Jiangxi 341000, China.

Received: 20 November 2013 Accepted: 27 December 2013

Published: 20 January 2014

\section{References}

1. Angervall L, Kindblom LG, Merck C: Myxofibrosarcoma. A study of 30 cases. Acta Pathol Microbiol Scand A 1977, 85A(2):127-140.

2. Weiss SW, Enzinger FM: Myxoid variant of malignant fibrous histiocytoma. Cancer 1977, 39(4):1672-1685.

3. Mentzel T, Calonje E, Wadden C, Camplejohn RS, Beham A, Smith MA Fletcher CD: Myxofibrosarcoma. Clinicopathologic analysis of 75 cases with emphasis on the low-grade variant. Am J Surg Pathol 1996, 20(4):391-405

4. Wang JG, Li YJ, Liu H, Zhao P: Primary cardiac myxofibrosarcoma: a case report and review of the literature. Tumori 2012, 98(6):e165-e168.

5. Kapur P, Sarode V: Pathologic quiz case: myxoid tibial lesion in a 31-year-old man. Low-grade myxofibrosarcoma. Arch Pathol Lab Med 2004, 128(4):e65-e66.

6. Marotta D, Angeloni M, Salgarello M, Ricciardella ML, Chalidis B, Maccauro G Surgical treatment of a giant tibial high-grade mixofibrosarcoma with preservation of limb function: a case report. Int Semin Surg Oncol 2009, 6:16.

7. Romeo S, Bovée JV, Kroon HM, Tirabosco R, Natali C, Zanatta L, Sciot R, Mertens F, Athanasou N, Alberghini M, Szuhai K, Hogendoorn PC, Dei Tos AP: Malignant fibrous histiocytoma and fibrosarcoma of bone: a re-assessment in the light of currently employed morphological, immunohistochemical and molecular approaches. Virchows Arch 2012, 461(5):561-570.

8. Murphey MD, Gross TM, Rosenthal HG: From the archives of the AFIP. Musculoskeletal malignant fibrous histiocytoma: radiologic-pathologic correlation. Radiographics 1994, 14(4):807-826

9. Nakayama K, Nemoto Y, Inoue Y, Mochizuki T, Soares SB Jr, Ohata K, Katsuyama J, Onoyama Y, Wakasa K: Malignant fibrous histiocytoma of the temporal bone with endocranial extension. AJNR Am J Neuroradiol 1997, 18(2):331-334.

10. Woodhams R, Kan S, Iwabuchi K, Oka H, Sagiuchi T, Hayakawa K: A case of malignant fibrous histiocytoma (MFH) in the skull bone presenting extensive permeative osteolysis. Radiat Med 2002, 20(3):141-145.

11. Park SW, Kim HJ, Lee JH, Ko YH: Malignant fibrous histiocytoma of the head and neck: CT and MR imaging findings. AJNR Am J Neuroradiol 2009, 30(1):71-76

12. Merck C, Angervall L, Kindblom LG, Odén A: Myxofibrosarcoma. A malignant soft tissue tumor of fibroblastic-histiocytic origin. A clinicopathologic and 
prognostic study of 110 cases using multivariate analysis. Acta Pathol Microbiol Immunol Scand Suppl 1983, 282:1-40.

13. Lin $X Y$, Wang $Y, Y U$ JH, Liu Y, Wang L, Li QC, Wang EH: Sclerosing rhabdomyosarcoma presenting in the masseter muscle: a case report. Diagn Pathol 2013, 8:18.

14. Peng L, Liu Y, Ai Y, Liu Z, He Y, Liu Q: Skull base metastases from a malignant solitary fibrous tumor of the liver. A case report and literature review. Diagn Pathol 2011, 6:127.

15. Binh MB, Sastre-Garau X, Guillou L, de Pinieux G, Terrier P, Lagacé R, Aurias A, Hostein I, Coindre JM: MDM2 and CDK4 immunostainings are useful adjuncts in diagnosing well-differentiated and dedifferentiated liposarcoma subtypes: a comparative analysis of 559 soft tissue neoplasms with genetic data. Am J Surg Pathol 2005, 29(10):1340-1347.

16. Oda Y, Takahira T, Kawaguchi K, Yamamoto H, Tamiya S, Matsuda S, Tanaka K, Kinukawa N, Iwamoto Y, Tsuneyoshi M: Altered expression of cell cycle regulators in myxofibrosarcoma, with special emphasis on their prognostic implications. Hum Pathol 2003, 34(10):1035-1042.

17. Kimura H, Dobashi Y, Nojima T, Nakamura H, Yamamoto N, Tsuchiya H, Ikeda H, Sawada-Kitamura S, Oyama T, Ooi A: Utility of fluorescence in situ hybridization to detect MDM2 amplification in liposarcomas and their morphological mimics. Int J Clin Exp Pathol 2013, 6(7):1306-1316.

18. Kuo JR, Chio CC, Wang CC, Chu YH, Lin KC, Chuang SS: Radiation-induced intra- and extra-cranial high-grade myxofibrosarcoma with tumor bleeding. J Clin Neurosci 2008, 15(10):1151-1154.

19. Tearada H, Nagata M, Mugiya S, Ozono S: High-grade myxofibrosarcoma presenting at the spermatic cord after radiotherapy for prostate cancer. BMJ Case Rep 2012. doi: 10.1136/bcr-03-2012-6082.

20. Urist MR: Trauma and neoplasm; report of a case of desmoid tumor following simple fracture of the radius and ulna. Am J Surg 1957, 93(4):682-688

21. Langer F, Pritzker KP, Gross AE, Shapiro II: Giant cell tumor associated with trauma. Clin Orthop Relat Res 1982, 164:245-248.

22. Oppenheimer BS, Oppenheimer ET, Danishefsky I, Stout AP: Carcinogenic effect of metals in rodents. Cancer Res 1956, 16(5):439-441.

23. McDougall $A$ : Malignant tumour at site of bone plating. J Bone Joint Surg $\mathrm{Br}$ 1956, 38-B(3):709-713.

24. Delgado ER: Sarcoma following a surgically treated fractured tibla; a case report. Clin Orthop 1958, 12:315-318.

25. Dube VE, Fisher DE: Hemangioendothelioma of the leg following metallic fixation of the tibia. Cancer 1972, 30(5):1260-1266.

26. Tayton KJ: Ewing's sarcoma at the site of a metal plate. Cancer 1980, 45(2):413-415.

27. McDonald I: Malignant lymphoma associated with internal fixation of a fractured tibia. Cancer 1981, 48(4):1009-1011.

28. Penman $\mathrm{HG}$, Ring PA: Osteosarcoma in association with total hip replacement. J Bone Joint Surg Br 1984, 66(5):632-634.

29. Bagó-Granell J, Aguirre-Canyadell M, Nardi J, Tallada N: Malignant fibrous histiocytoma of bone at the site of a total hip arthroplasty. A case report. J Bone Joint Surg Br 1984, 66(1):38-40.

30. Swann M: Malignant soft-tissue tumor at the site of a total hip replacement. J Bone Joint Surg Br 1984, 66(5):629-631.

31. Weber PC: Epithelioid sarcoma in association with total knee replacement. A case report. J Bone Joint Surg Br 1986, 68(5):824-826.

32. Hughes AW, Sherlock DA, Hamblen DL, Reid R: Sarcoma at the site of a single hip screw. A case report. J Bone Joint Surg Br 1987, 69(3):470-472.

33. Haag $M$, Adler CP: Malignant fibrous histiocytoma in association with hip replacement. J Bone Joint Surg Br 1989, 71(4):701.

34. Sunderman FW Jr: Carcinogenicity of metal alloys in orthopedic prostheses: clinical and experimental studies. Fundam Appl Toxicol 1989, 13(2):205-216.

35. Ward JJ, Thornbury DD, Lemons JE, Dunham WK: Metal-induced sarcoma. A case report and literature review. Clin Orthop Relat Res 1990, 252:299-306.

36. Khurana JS, Rosenberg AE, Kattapuram SV, Fernandez OS, Ehara S: Malignancy supervening on an intramedullary nail. Clin Orthop Relat Res 1991, 267:251-254.

37. Gatti GM, Ivaldi GB, Lartigau E, Marsiglia H, Orecchia R: A Case of RhabdomyoSarcoma Following a Metal Surgical Implant. Sarcoma 1999, 3(2):145-147.

38. Hinarejos P, Escuder MC, Monllau JC, Alvarez P, Lloreta J, Ballester J: Fibrosarcoma at the site of a metallic fixation of the tibia-a case report and literature review. Acta Orthop Scand 2000, 71(3):329-332.
39. Adams JE, Jaffe KA, Lemons JE, Siegal GP: Prosthetic implant associated sarcomas: a case report emphasizing surface evaluation and spectroscopic trace metal analysis. Ann Diagn Pathol 2003, 7(1):35-46.

40. Albert A, Lootvoet L, Lejeune E, Beugnies A, Himmer O: Angiosarcoma around a knee arthroplasty. Report of a case and literature review. Acta Orthop Belg 2009, 75(4):549-553.

41. Palraj B, Paturi A, Stone RG, Alvarez H, Sebenik M, Perez MT, Bush LM: Soft tissue anaplastic large T-cell lymphoma associated with a metallic orthopedic implant: case report and review of the current literature. J Foot Ankle Surg 2010, 49(6):561-564.

42. Dorrestijn O, Jutte PC: Osteosarcoma in the distal femur two years after an ipsilateral femoral shaft fracture: a case report. J Med Case Rep 2011, 5:198.

43. Nuevo-Ordóñez Y, Montes-Bayón M, Blanco-González E, Paz-Aparicio J, Raimundez JD, Tejerina JM, Peña MA, Sanz-Medel A: Titanium release in serum of patients with different bone fixation implants and its interaction with serum biomolecules at physiological levels. Anal Bioanal Chem 2011, 401(9):2747-2754.

44. Coen N, Kadhim MA, Wright EG, Case CP, Mothersill CE: Particulate debris from a titanium metal prosthesis induces genomic instability in primary human fibroblast cells. Br J Cancer 2003, 88(4):548-552.

doi:10.1186/1746-1596-9-6

Cite this article as: Li et al.: Low-grade myxofibrosarcoma following a metal implantation in femur: a case report. Diagnostic Pathology 2014 9:6.

\section{Submit your next manuscript to BioMed Central and take full advantage of:}

- Convenient online submission

- Thorough peer review

- No space constraints or color figure charges

- Immediate publication on acceptance

- Inclusion in PubMed, CAS, Scopus and Google Scholar

- Research which is freely available for redistribution

Submit your manuscript at www.biomedcentral.com/submit
C) Biomed Central 